\title{
Neighborhood Social Environment and Risk of Death: Multilevel Evidence from the Alameda County Study
}

Irene H. Yen ${ }^{1}$ and George A. Kaplan ${ }^{2}$

\begin{abstract}
Recent reports suggest the importance of associations between residential area characteristics and health status, but most research uses only census data to measure these characteristics. The current research examined the effect of overall neighborhood social environment on 11-year risk of death. On the basis of data, the authors developed a three-component neighborhood social environment scale: 1) commercial stores; 2) population socioeconomic status; and 3) environment/housing. Data from the 1983 wave of the Alameda County Study $(n=1,129)$ and deaths over 11 years were analyzed with two-level logistic regression models. Age- and sex-adjusted risk of death was higher for residents in low social environment neighborhoods (odds ratio $=1.58$, $95 \%$ confidence interval 1.15-2.18). Mortality risks were significantly higher in neighborhoods with a low social environment, even after account was taken of individual income level, education, race/ethnicity, perceived health status, smoking status, body mass index, and alcohol consumption. When each component of the neighborhood social environment characteristics score was examined separately, each was found to be associated with higher risk for mortality, independent of individual risk factors. These findings demonstrate the role of area characteristics as a health risk factor and point to the need for more focused attention to the meaning and measurement of neighborhood quality. Am J Epidemiol 1999;149:898-907.
\end{abstract}

mortality; social class; social environment; socioeconomic factors

This study investigates whether neighborhood social environment is associated with 11-year mortality risk, after adjustment for individual risk factors. Neighborhood social environment is measured with both census data and area data to capture the context created by people and place.

Since the 1970s, several studies (1-16) have reported associations between residential area and all-cause mortality. Taken together, these studies have suggested the important contribution of area characteristics to mortality risk. However, design, methodological, and analytic limitations of the studies leave important questions unanswered. Most of these studies were cross-sectional and had group-level data instead of individual-level outcome data. Therefore, causal conclusions or individual-level inferences are difficult. Measurement approaches were limited in that mea-

Received for publication February 24, 1998, and accepted for publication September 21, 1998.

Abbreviations: $\mathrm{Cl}$, confidence interval; $O R$, odds ratio; SES, socioeconomic status.

${ }^{1}$ School of Public Health, University of California, Berkeley, CA.

2 School of Public Health, University of Michigan, Ann Arbor, MI.

Reprint requests to Dr. Irene H. Yen, Behavioral Risk Factors Training Program, School of Public Health, 140 Warren Hall, Box 7360 , University of California, Berkeley, CA $94720-7360$. surement of area in these studies relied primarily on census data. Investigators usually chose census variables that were aggregated from individual data, such as percent unemployed, percent income below poverty level, and percent single head of household with children. Data limited to the characteristics of individuals in an area cannot fully describe the physical or social environment. Interpreting their own findings, the authors of these studies using census data suggested that the census data were proxies for crime, inadequate housing, stress, and inadequate local resources. Other authors have proposed measures that directly address these latter characteristics, such as recreational facilities, public transportation services, health centers, dental practices, pharmacies, and crime rates $(15,17)$. The urban planning literature further points to presence of commercial stores, churches, schools, vandalism, graffiti, liquor stores, and bars as important measures of social environment $(18,19)$.

Recent research has moved beyond using census measures exclusively to describe area characteristics $(15,20)$. This work has used such indicators as number of active neighborhood community groups, per capita crime rates, distance to services, and perceptions of problems (e.g. litter, traffic). These more recent studies 
have demonstrated associations between area characteristics and low birth weight (15), depression (20), and perceived health status (20).

This report presents a longitudinal analysis of the effects of area characteristics on risk of death, using a combination of census and area-based data and twolevel regression models to assess the contribution of area to variations in outcome, as separate from the contributions of individual level factors.

\section{MATERIALS AND METHODS}

\section{The Alameda County Study}

Data for this study were collected by the Human Population Laboratory Section of the California Department of Health Services. Respondents were part of the original cohort of 6,928 persons selected in 1965 to represent the noninstitutionalized adult residents of the county. Respondents provided information through self-adrninistered questionnaires. Subsequent questionnaires were mailed to those who were still alive and had known addresses in 1974, 1983, 1994, and 1995. In 1983, a representative 50 percent subsample was surveyed. Computerized death clearance, coupled with intensive tracing efforts, identified deaths during the periods between the study waves. In addition, thorough tracing procedures were used to minimize loss to follow-up between waves. Ninety-four percent of the surviving members of the 1983 sample were located, and 87 percent of those contacted returned questionnaires. Detailed procedures for the study have been reported elsewhere $(21,22)$.

All participants in the 1983 wave of the Alameda County Study who lived in Alameda County, California, were included in this analysis $(n=1,129$; ages 36-96 years). Mortality has been ascertained through December 31, 1994.

\section{Neighborhood social environment score}

We wanted to measure 1983 neighborhood social environment, including population and place domains. In the discussion sections of prior studies of neighborhood environment, authors suggested that lack of access to services and stores may be one of the reasons for observed poor health outcomes $(13,15-17)$. To that end, we collected information in three categories: common commercial stores (grocery stores, supermarkets, laundries/dry cleaners, beauty parlors/barber shops, and pharmacies), other area descriptors (injury motor vehicle crashes and parks), and 1980 census data ( percent white-collar employees, percent renters, percent single-family dwellings, crowding, percent black, per capita income, population of census tract, geographic area of census tract). We selected stores that most people need on a regular basis.

The selection of census variables was based on previous research, but with an emphasis on variables that were not aggregated population data (e.g., percent with incomes below the poverty level). The latter were not included in order to avoid the tautology, "Poor people live in areas where there are more poor people." Aggregated population characteristics in some cases may reflect compositional characteristics only and not the collective properties of areas (23). The proportion of blacks in an area, although an aggregate variable, was used, since there is strong documentation of structural forces leading to residential segregation of blacks (24-28).

Neighborhood was defined as census tract and will refer to census tract in the remainder of this paper. Data were collected and then factor analyzed to identify clusters of related variables. These clusters were then combined to formulate an overall measure of neighborhood environment. Using this measure, we classified 1983 neighborhoods in Alameda County. This approach is similar to the social area analysis approach of Shevky and Bell (29); we assume that neighborhoods with similar characteristics have similar influences.

The names and addresses of common commercial stores (i.e., grocery stores, supermarkets, pharmacies, beauty pariors or barber shops, and laundromats or dry cleaners) were collected from the Yellow Pages of telephone books for 1980, 1983, or 1984 (in some cases, 1983 was not available). The location of all parks (either street address or intersection) in Alameda County data were available from local Parks and Recreation departments. The Department of California Highway Patrol maintains a computer record of every motor vehicle crash that results in injury. The location of the intersection of the crash was available. Stores, parks, and motor vehicle crashes were geocoded to census tracts. The number of stores per 1,000 people in the census tract was calculated to measure access to services. Finally, census data, based on previous research, were selected from the 1980 census. Since we were unable to ascertain retrospectively the amount of graffiti and vandalism, we could not include these variables. In addition, no reliable sources of complete address listings of churches, public transportation lines, crime occurrences, liquor stores, and bars were available. Therefore, these items could not be included.

For the factor analysis, neighborhoods were ranked by each variable, e.g., number of grocery stores per 1,000 population or per capita income. The rank of the neighborhoods for each variable was entered into the factor analysis so that all of the variables would have comparable units in the analysis (30). Order of ranks 
was determined a priori based on whether or not higher values of the variable were thought to be associated with higher- or lower-quality neighborhood social environment. In cases in which it was difficult to determine a priori the ordering of ranks, the sign of the factor-loading coefficient directed the decision. Clusters of neighborhood characteristics were identified by factor analyzing the variables with orthogonal rotation.

To decrease collinearity between resulting factors, variables that loaded high on more than one factor were removed. Only variables that loaded above 0.55 were retained. The factor analysis eliminated four variables and produced three interpretable components of neighborhood social environment (table 1). The variables loading on each component are shown below with their descriptions. Taken together, the three components explained 64.9 percent of the variation of all neighborhoods in the county.

A neighborhood social environment score was created by combining the three components identified by the factor analysis. Each variable was given equal weighting to preserve interpretability of the score. The score was created using the following procedure: 1) a component (i.e., population socioeconomic status (SES), commercial stores, environment/housing) measure was calculated by summing the variables' ranks; 2 ) the measure was divided into quartiles, and each quartile was assigned a value of $1-4$; and 3 ) the three component measures were summed, giving a score with a range of 3-12. Low-quality neighborhood social envi- ronment was defined as having a score in the lowest. tertile of the scores for all neighborhoods in Alameda County less than or equal to 6.

Table 2 indicates definitions of the measures of income, education, race/ethnicity, smoking, body mass index, alcohol consumption, and perceived health status.

\section{Analysis}

Two-level logistic regression models were used; level 1 refers to individuals, and level 2 refers to neighborhoods. All level 1 predictors were entered as fixed effects. Fixed effects modeling assumes that the level 1 predictors and the outcome are related in the same way across level 2 units $(31,32)$. The association between overall neighborhood social environment and mortality was examined. In addition, each component ("population SES" (Chronbach's alpha =0.90), "commercial stores" (Chronbach"s alpha $=0.65$ ), and "environment/housing" (Chronbach's alpha $=0.54)$ ) was examined separately as a predictor for mortality.

Analyses were conducted in four stages. The first stage examined age- and sex-adjusted models. Next, models adjusting separately for individual income level, education, race/ethnicity, perceived health, smoking status, body mass index, and alcohol consumption were evaluated. Then a model simultaneously adjusting for all potential confounders was tested. Since income and education are strongly associated

TABLE 1. Components of neighborhood social environment score

\begin{tabular}{|c|c|c|}
\hline Variable & Description & Rank direction \\
\hline \multicolumn{3}{|c|}{ Population socioeconomic status } \\
\hline Per capita income & Dollars & $\begin{array}{l}\text { Ascending rank order (as it } \\
\text { increases, rank increases) }\end{array}$ \\
\hline White-collar employees & $\begin{array}{l}\% \text { of employed people who have white- } \\
\text { collar positions, based on occupation } \\
\text { codes: executive and managerial } \\
\text { (003-037), professional (043-199), } \\
\text { technicians (203-235), sales ( } 243- \\
285), \text { and administrative support } \\
(303-389)^{*}\end{array}$ & Ascending \\
\hline Crowding & $\%>1.01$ person/room & $\begin{array}{l}\text { Descending (as it increases, } \\
\text { rank decreases) }\end{array}$ \\
\hline \multicolumn{3}{|l|}{ Commercial stores } \\
\hline Pharmacy & Counts per 1,000 people & Descending \\
\hline Beauty salon/barber shop & Counts per 1,000 people & Descending \\
\hline Laundry/dry cleaner & Counts per 1,000 people & Descending \\
\hline Supermarket & Counts per 1,000 people & Descending \\
\hline \multicolumn{3}{|l|}{ Environment/housing } \\
\hline Population of census tract & No. of people of all ages & Ascending \\
\hline Area of census tract & Square miles & Ascending \\
\hline Renters & $\%$ of househoids renting & Descending \\
\hline Single-family dwellings & $\%$ of single-unit housing structures & Ascending \\
\hline
\end{tabular}

* Reference 37 and Casper, Centers for Disease Control and Prevention, 1996. 
TABLE 2. Definition of independent variables, Alameda County Study, 7983

\begin{tabular}{|c|c|}
\hline Variable & Detinition \\
\hline Income & $\begin{array}{l}\text { Reported from all sources for the family in } 18 \text { categories. A number was assigned } \\
\text { to each category: } \$ 2,000 \text { tor the under } \$ 2,000 \text { category, } \$ 50,000 \text { for the } \\
\$ 50,000 \text { or more category, and midpoints for all other categories in between. } \\
\text { Income was dichotomized for the lowest quartile ( } 23 \%) \text { versus all others }(77 \%) \text {. }\end{array}$ \\
\hline Education & $\begin{array}{l}\text { Less than high school ( } \leq 11 \text { years of schooling: } 28 \% \text { ), high school graduate (12 } \\
\text { years: } 31 \% \text { ), more than high school ( } \geq 13 \text { years: } 41 \% \text { ) }\end{array}$ \\
\hline Race/ethnicity & Classified into two categories: black (12\%) and all others $(88 \%)$ \\
\hline Smoking status & Current smoker $(27 \%)$, former smoker $(30 \%)$, never smoker $(43 \%)$ \\
\hline Body mass index & $\begin{array}{l}\text { Calculated with weight in kilograms divided by height in meters squared and } \\
\text { classified into two categories: obese (25\%) and all others (75\%). Categories } \\
\text { were created using the Second National Health and Nutrition Examination } \\
\text { Survey standards. Obese was defined as the top 15th percentile (38) }\end{array}$ \\
\hline Alcohol consumption & $\begin{array}{l}\text { No. of drinks of wine, beer, and liquor per month was classified into } 0 \text { (abstainers, } \\
20 \% \text { ), greater than } 60 \text { (heavy, } 8 \% \text { ), and others (reference, } 71 \% \text { ). }\end{array}$ \\
\hline Perceived health status & $\begin{array}{l}\text { Measured by the response to the question, "All in all, would you say your health is } \\
\text { excellent, good, fair, or poor?" Responses were classified into two categories: } \\
\text { fair/poor }(21 \%) \text {, good/excellent ( } 79 \%) \text {. }\end{array}$ \\
\hline
\end{tabular}

with each other, when simultaneously adjusted for individual factors they were not included together. (The odds ratio of people with less than 12 years of education compared with individuals in the lowest quartile of income was 4.36 (95 percent confidence interval (CI) 3.22-5.90.) Finally, cross-level interaction effects were investigated between all level 1 variables and the level 2 variable of interest.

Analyses were conducted using HLM version 4.01 . for Windows (32) and SAS version 6.09 on a SUN SPARC station.

\section{RESULTS}

There were 1,129 people in the sample living in Alameda County in 1983. After removing people who had missing values for income, education, race/ethnicity, smoking status, perceived health status, body mass index, and alcohol consumption, there were 996 people (88.2 percent) remaining in the data set. People who were excluded had a tendency to be older (mean age, 61.6 vs. 58.8 years) and were more likely to have less than 12 years of schooling ( 31 vs. 27 percent). Otherwise, they had similar income levels (mean income, $\$ 24,445$ vs. $\$ 25,694$ ), were almost equally likely to die during the follow-up period ( 23 vs. 22 percent), were equally likely to be black ( 12 vs. 12 percent), and were similarly likely to report fair or poor perceived health status ( 23 vs. 21 percent). The mean age of the sample was 58.9 years, there were more women ( 57 percent) than men, 88 percent were white or other, 12 percent were black, and more than onequarter ( 28 percent) did not graduate from high school. Of the 996 people alive in 1983,228 had died by the end of 1994 (table 3 ). Those who died were older, and were more likely to be male $(p=0.09)$, to have a lower income, to be less well-educated, and to describe themselves as being in poorer health.

\section{Neighborhood social environment score}

People living in the low social environment neighborhoods were more likely to die in the 11-year period of follow-up (83 of 271 (31 percent)) than were those living in the high social environment neighborhoods (145 of 725 (20 percent), $p<0.0001)$. Using two-level logistic regression models, adjusting for sex and age in 1983, the odds ratio for mortality for people living in the low social environment neighborhoods was 1.58 (95 percent confidence interval 1.15-2.18) compared with people living in the high social enviromment neighborhoods (table 4). Controlling individually for income, education, alcohol consumption, and perceived health status, a lower, but still significant, elevated risk of mortality was observed. No cross-level interaction effects were found. Those who lived in a low social enviroment neighborhood had a 58 percent increased odds of dying compared with people who lived in a high social environment neighborhood after simultaneously adjusting for all individual covariates (95 percent CI 1.13-2.24). 
TABLE 3. Baseline demographic characteristics of Alameda County residents relative to vital status by the end of follow-up, Alameda County Study, 1983-1994

\begin{tabular}{|c|c|c|c|c|c|c|}
\hline \multirow{2}{*}{ Variable } & \multirow{2}{*}{$\begin{array}{c}\text { Overalt } \\
(n=996)\end{array}$} & \multicolumn{2}{|c|}{ Alive $(n=768)$} & \multicolumn{2}{|c|}{ Deceased $(n=228)$} & \multirow{2}{*}{$\begin{array}{c}P \\
\text { value }\end{array}$} \\
\hline & & No. & $\%$ & No. & $\%$ & \\
\hline Sex & & & & & & 0.093 \\
\hline Male & 428 & 319 & 75 & 109 & 25 & \\
\hline Female & 568 & 449 & 79 & 119 & 21 & \\
\hline Age (mean years) & 58.9 & 55.2 & & 71.2 & & 0.02 \\
\hline Income (mean dollars) & 25,720 & 28,258 & & 17,173 & & 0.02 \\
\hline Race/ethnicity & & & & & & NS* \\
\hline White and others & 873 & 673 & 77 & 200 & 23 & \\
\hline Black & 123 & 95 & 77 & 28 & 23 & \\
\hline Education (years) & & & & & & $<0.0001$ \\
\hline$\leq 11$ & 278 & 187 & 67 & 91 & 33 & \\
\hline High school graduate & 305 & 236 & $\pi$ & 69 & 23 & \\
\hline$\geq 13$ & 413 & 345 & 84 & 68 & 16 & \\
\hline Smoking & & & & & & NS \\
\hline Never & 432 & 334 & 77 & 98 & 23 & \\
\hline Current & 267 & 208 & 78 & 59 & 22 & \\
\hline Former & 297 & 226 & 76 & 71 & 24 & \\
\hline Perceived health status & & & & & & 0.02 \\
\hline Excellentgood & 788 & 641 & 81 & 147 & 19 & \\
\hline Fair/poor & 208 & 127 & 61 & 81 & 39 & \\
\hline Body mass index & & & & & & 0.02 \\
\hline Obese & 246 & 203 & 83 & 43 & 17 & \\
\hline All others & 750 & 565 & 75 & 185 & 25 & \\
\hline Alcohol consumption & & & & & & 0.02 \\
\hline Abstainers & 201 & 133 & 66 & 68 & 34 & \\
\hline Heavy & 85 & 70 & 82 & 15 & 18 & \\
\hline All others & 710 & 565 & 80 & 145 & 20 & \\
\hline
\end{tabular}

* NS, nonsignificant.

TABLE 4. Neighborhood social environment and 11-year risk of death, 2-level logistic regression, Alameda County Study, 1983-1994 $(n=996)$

\begin{tabular}{|c|c|c|}
\hline \multirow[t]{2}{*}{$\begin{array}{l}\text { Variables included } \\
\text { in the model }\end{array}$} & \multicolumn{2}{|c|}{$\begin{array}{l}\text { Mortality associated with low } \\
\text { neighborhood social } \\
\text { environment score* }\end{array}$} \\
\hline & ORt & $95 \% \mathrm{Cl} \dagger$ \\
\hline Age (years in 1983), sex & 1.58 & $1.15-2.18$ \\
\hline+ Individual income ( $\$ \$ 12,000$ vs. all others) & 1.40 & $1.01-1.95$ \\
\hline+ Education ( $\leq 11$ years, 12 , vs. $\geq 13$ ) & 1.57 & $1.14-2.16$ \\
\hline + Race/ethnicity (black vs. all others) & 1.63 & $1.17-2.28$ \\
\hline + Smoking (current, former, vs. never) & 1.65 & $1.19-2.29$ \\
\hline+ Body mass index (obese vs. all others) & 1.61 & $1.17-2.21$ \\
\hline + Alcohol consumption (abstainers, heavy, vs. all others) & 1.55 & $1.12-2.15$ \\
\hline $\begin{array}{l}\text { + Perceived health status (fair/poor vs. excellent/good) } \\
+ \text { Individual income, race/ethnicity, smoking, body mass index, }\end{array}$ & 1.48 & $1.07-2.05$ \\
\hline alcohol, and perceived health status & 1.58 & $1.13-2.24$ \\
\hline
\end{tabular}

* Low tertile compared with the rest.

$+\mathrm{OR}$, odds ratio; $\mathrm{Cl}$, confidence interval.

\section{Commercial stores}

After adjusting for age in 1983 and sex, this study found that people living in the neighborhoods with many commercial stores had an increased risk of death (odds ratio $(\mathrm{OR})=1.40,95$ percent CI $1.02-1.93$ ) compared with people living in neighborhoods with few stores (table 5). Further, controlling individually 
for income, education, smoking, race/ethnicity, body mass index, alcohol consumption, and perceived health status made little difference. No cross-level interaction effects were found. When all covariates were simultaneously adjusted for, those who lived in neighborhoods with many stores had 32 percent increased odds of dying compared with people who lived in neighborhoods with few stores (OR $=1.32,95$ percent CI 0.94-1.85).

\section{Environment/housing}

When sex and age in 1983 were adjusted for, people living in neighborhoods with low scores had an increased risk of death $(\mathrm{OR}=1.56,95$ percent $\mathrm{CI}$ 1.13-2.15) compared with people living in neighborhoods with high scores. A significant increased risk of death was observed when controlling individually for income, education, smoking, race/ethnicity, body mass index, alcohol consumption, and perceived health status.

In further analyses, the association between neighborhood environment/housing and risk for death differed by individual income level. For those who had higher income, the risk for mortality was equal regardless of where they lived (OR $=1.02,95$ percent $\mathrm{CI}$ 0.66-1.57). People with lower incomes had an elevated risk in either neighborhood, but an especially high risk in the low environment/housing neighborhood (OR = $3.83, p=0.02$ ) (Note that HLM version 4.01 does not provide the variance covariance matrix so the calculation of the 95 percent confidence interval of the odds ratio was not possible.) When all other covariates are adjusted for separately, the interaction effects persist. The interaction effects persist when simultaneously adjusted for smoking and perceived health status (figure 1).

\section{Population SES}

After adjustment for age in 1983 and sex, this study found that people living in the lowest population SES neighborhoods had an increased risk of death (population SES quartile 1: $O R=1.53,95$ percent $\mathrm{Cl}$ 0.91-2.57) compared with people living in the highest population SES neighborhoods (population SES quartile 4). Those in the intermediate population SES neighborhoods also had elevated risk for mortality (population SES quartile 2: $\mathrm{OR}=1.34,95$ percent $\mathrm{CI}$ 0.90-2.01; population quartile $3: O R=1.48,95$ percent CI 0.96-2.29). Similar results were obtained when we individually adjusted for income, education, smoking, race/ethnicity, body mass index, alcohol consumption, and perceived health status, although income and perceived health status had especially strong confounding effects (table 5).

In further analyses, the association between neighborhood population SES and risk of death differed by individual income level. Overall, people with a lower

TABLE 5. Neighborhood commercial stores, environment/housing, and population SES* and 11-year risk of death, 2-level logistic regression, Alameda County Study, 1983-1984 $(n=996)$

\begin{tabular}{|c|c|c|c|c|c|c|}
\hline \multirow[t]{2}{*}{$\begin{array}{l}\text { Variables inciuded } \\
\text { in the model }\end{array}$} & \multicolumn{2}{|c|}{$\begin{array}{l}\text { High no. of commercial } \\
\text { slores (reference: } \\
\text { low no. of stores)t }\end{array}$} & \multicolumn{2}{|c|}{$\begin{array}{l}\text { High environment/ } \\
\text { housing score } \\
\text { (reference: low score)t }\end{array}$} & \multicolumn{2}{|c|}{$\begin{array}{l}\text { Population SES } \\
\text { quartile } 1 \\
\text { (reference: quartile 4) } \neq\end{array}$} \\
\hline & OR* & $95 \% \mathrm{Cl}^{*}$ & OR & $95 \% \mathrm{Cl}$ & OR & $95 \% \mathrm{Cl}$ \\
\hline $\begin{array}{l}\text { Age (years in 1983), sex } \\
+ \text { Individual income ( } \$ \$ 12,000 \text { vs. all }\end{array}$ & 1.40 & $1.02-1.93$ & 1.56 & $1.13-2.15$ & 1.53 & $0.91-2.57$ \\
\hline others) & 1.42 & $1.03-1.96$ & 1.39 & $1.00-1.93$ & 1.08 & $0.75-1.91$ \\
\hline + Education ( $\leq 11$ years, 12, vs. $\geq 13$ ) & 1.37 & $1.00-1.89$ & 1.54 & $1.12-2.14$ & 1.51 & $0.87-2.62$ \\
\hline + Race/ethnicity (black vs. all others) & 1.40 & $1.02-1.93$ & 1.60 & $1.16-2.22$ & 1.64 & $0.88-3.05$ \\
\hline $\begin{array}{l}\text { + Smoking (current, former, vs. never) } \\
\text { + Body mass index (obese vs. all }\end{array}$ & 1.31 & $0.94-1.82$ & 1.59 & $1.14-2.24$ & 1.56 & $0.91-2.68$ \\
\hline $\begin{array}{l}\text { others) } \\
+ \text { Alcohol (abstainers, heavy, vs.all }\end{array}$ & 1.40 & $1.02-1.92$ & 1.60 & $1.16-2.22$ & 1.58 & $0.95-2.66$ \\
\hline $\begin{array}{l}\text { + Alcohol (abstainers, heavy, vs.all } \\
\text { others) } \\
+ \text { Perceived health status (fair/poor vs. }\end{array}$ & 1.40 & $1.02-1.93$ & 1.54 & $1.11-2.13$ & 1.47 & $0.85-1.53$ \\
\hline excellent/good) & 1.39 & $1.01-1.81$ & 1.48 & $1.07-2.05$ & 1.26 & $0.74-2.14$ \\
\hline $\begin{array}{l}\text { + Individual income, race/ethnicity, } \\
\text { smoking, body mass index, } \\
\text { alcohol, and perceived health status }\end{array}$ & 1.32 & $0.94-1.85$ & & $-\S$ & & $-\S$ \\
\hline
\end{tabular}

* SES, socioeconomic status; $\mathrm{OR}$, odds ratio; $\mathrm{Cl}$, confidence interval.

FES, socioeconomic status, OR, odds rath; Cl, confidence interialian.

For population SES, scores were divided into quartiles. The odds ratios shown here are for the lowest quartile of population SES, using the highest quartile as the reference.

$\$$ Odds ratios are not reported for this model because of an interaction effect between the neighborhood score and individual income (see figures 1 and 2). 


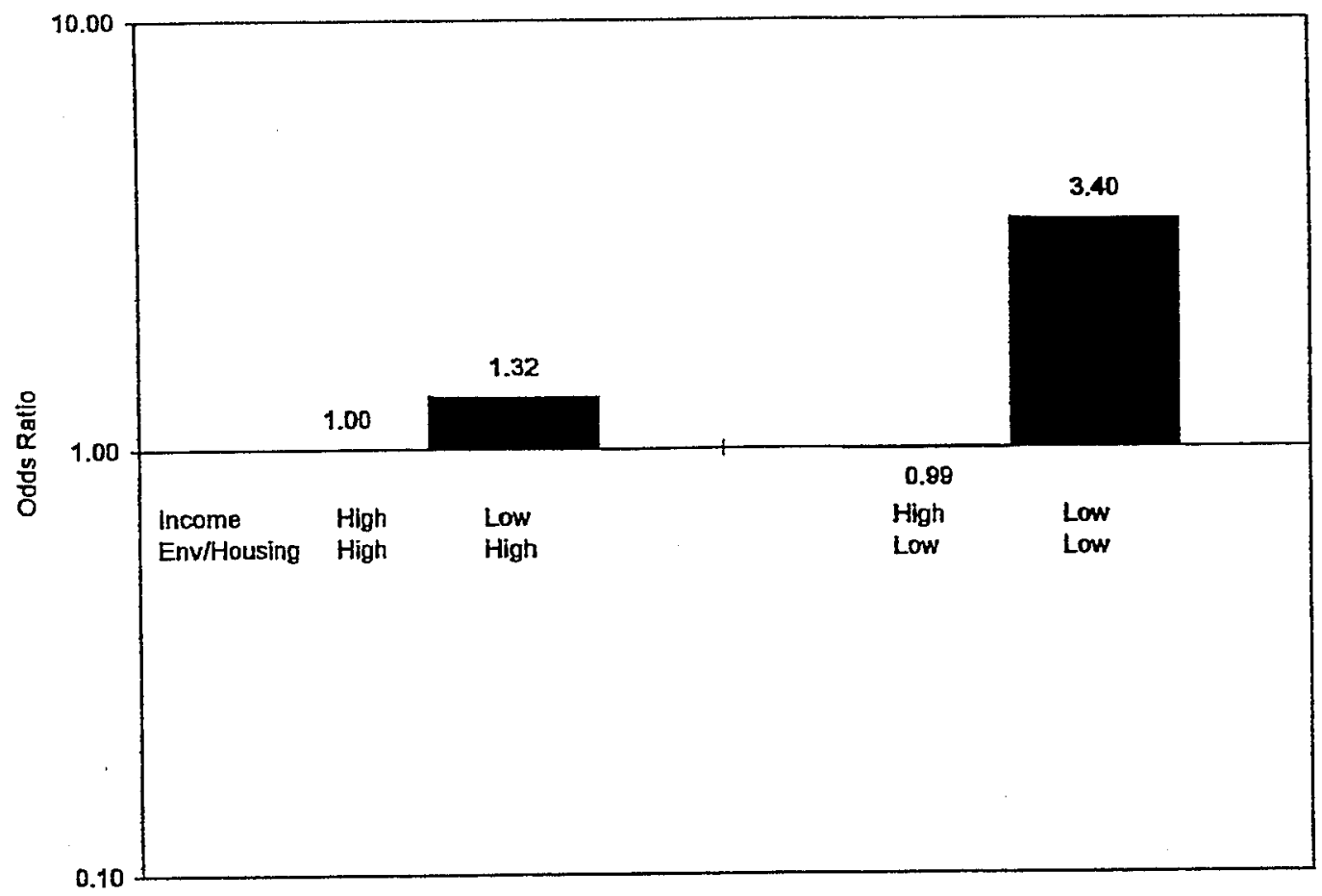

FIGURE 1. Association between environment/housing score by income and 11-year risk of death, adjusted for smoking and perceived health status: two-level logistic regression analysis, Alameda County Study, California, 1983-1994.

income had higher risk of death than did people with higher income, regardless of the population SES level. However, lower-income people had the highest risk in the highest population SES category, quartile 4 (OR = 5.53, $p<0.001$ ). These interaction effects persisted after adjusting individually for all other covariates and concurrently for smoking and perceived health status (figure 2).

\section{DISCUSSION}

The results of these analyses indicate that lowerquality social environments are associated with an increased risk of death during an 11-year follow-up period. This association persisted after adjustment for age, sex, individual income, education, race/ethnicity, smoking status, body mass index, alcohol consumption, and perceived health status. These findings suggest that neighborhood characteristics such as income level of the population, percent employed in whitecollar occupations, presence of stores, and types of housing available contribute to a person's risk of death in addition to individual risk factors. When each of the neighborhood social environment score components was examined separately, it was found that scores for population SES, commercial stores, and environment/housing each predicted risk for of death, adjust- ing for individual risk factors. The separate components of social environment are related, although not strongly. The correlation coefficient between population SES and environment/housing is 0.369 ( $p<$ 0.001 ), and that between environment/housing and commercial stores is $0.318(p<0.001)$; population SES and commercial stores are not correlated $(R=$ $0.040, p=0.49$ ). Assessing the effect of neighborhood social environment overall provides different information than assessing each of the components separately.

Evaluating confounding in these models is not straightforward. The common definition of confounding indicates that a variable that is on the pathway between the exposure and outcome is not a confounder. Except for age and sex, all of the individual covariates tested in these models could be considered to be on the causal pathway. The case of race/ethnicity is an example. Race/ethnicity, the racial/ethnic composition of a neighborhood, and neighborhood social environment are all related. A body of research has documented the connection between US structural forces and the residential segregation of black people, in particular, and of Latinos to a lesser extent (24-28). Therefore, one's race/ethnicity could be "in the causal pathway" between neighborhood social environment and mortality. Using similar reasoning, individual income and perceived health status could also be considered to be 


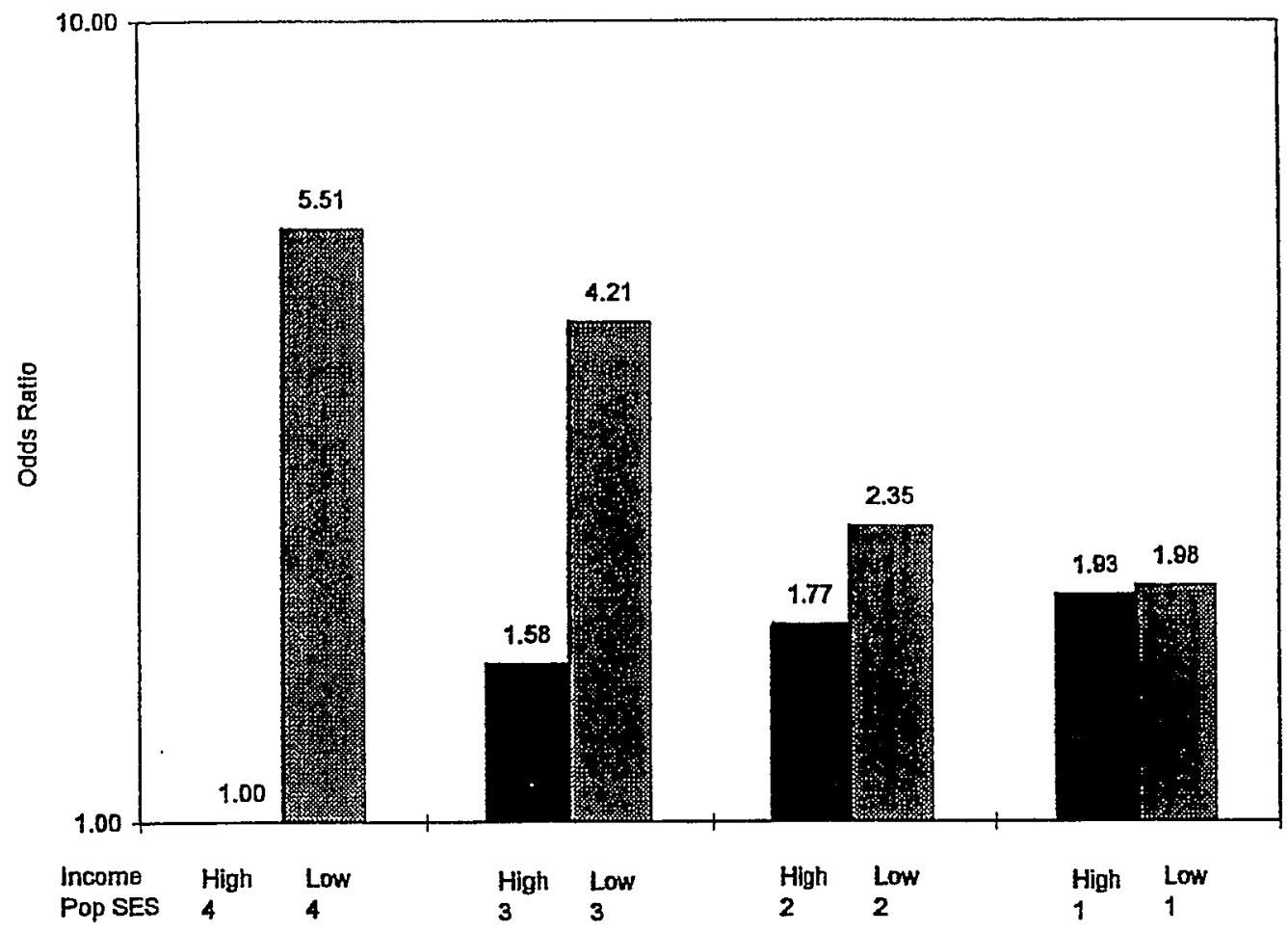

FIGURE 2. Association between population SES score by income and 11 -year mortality risk, adjusted for smoking and perceived health status: two-level logistic regression analysis, Alameda County Study, California, 1983-1994.

in the causal pathway. Low median income areas are composed of more low-income people, perhaps in part because people with higher incomes have the resources to move to more desirable locations, leaving an increasing concentration of low-income people. In the case of perceived health status, previous analyses of 1965 and 1974 Alameda County Study data demonstrated that for people who had excellent or good perceived health status, "poverty area" residence in 1965 was associated with an increased risk of fair or poor perceived health status in 1974 compared with those who lived in the nonpoverty area (34). However, we thought that it was important to investigate the effect of the social environment after taking into consideration these characteristics.

We also found that as the population SES level increases, a low-income person's risk increases, suggesting differential access to resources in the high population SES neighborhoods. In high SES areas where there are more resources, people with low income may have unequal access to those resources compared with those with high income. The finding also suggests that low population SES neighborhoods level out the effect of higher income, since risk levels in the lowest neighborhoods were nearly equal. These results are similar to our finding of the effects of poverty-area residence on change in leisure-time physical activity (33). There was little difference in physical activity level change between income groups of people living in a poverty area. However, in the nonpoverty area, there was a decline in physical activity for people with a low income compared with almost no change for people with a high income.

There are methodological limitations that may affect our interpretation of the findings. The neighborhood is defined as a census tract, which the Bureau of the Census defines as "a relatively homogeneous area with respect to population characteristics, economic status, and living conditions with an average population of 4,000 " (35, p. 254). However, the urban planning literature suggests using the distance one can cover in a 5to 10 -minute walk or three to four city blocks $(18,19)$. If the census tract does not carry neighborhood meaning for residents, this would lead to nondifferential misclassification, resulting in a bias toward the null.

Commercial stores were ascertained using telephone book Yellow Pages listings. All business telephone numbers are given complimentary Yellow Pages listings. Unofficial businesses would not have been counted. Only beauty parlors/barber shops might have been underascertained. Most likely, the unofficial beauty parlors/barber shops were in the lower-quality 
areas, which already had a high concentration of stores. In that case, the neighborhood socioenvironmental characteristics classification would not have been affected by better ascertainment.

Length of residence at the subject's address from 1983 was not considered, nor was residential mobility. In both instances, the resulting misclassification would lead to an underestimate of the association. People who were living in the low-quality area in 1983 may have chosen to do so. Some may have been living there because they could not move elsewhere. This selection problem would lead to estimates biased away from the null, assuming that mobile wealthy people are moving to "better" environments and mobile poor people are moving to "worse" environments. A previous analysis of this population did find that when people moved, they tended to move to similar places, rather than to better or worse places (36). Selection issues cannot be ignored when examining environmental variables. It is always possible that aggregate effects simply reflect compositional differences between those who live in different areas. By adjusting for a wide range of individual characteristics, we remove many of these differences. Furthermore, adjustment for perceived health status, a strong predictor of risk of death, removes some of the prior effects of compositional differences. Nevertheless, it is also possible that unknown confounders, which partially explain how individuals sort themselves across residential areas not included in the models, would further reduce the magnitude of the neighborhood effect.

The current sample is not a representative sample of a population. The sample analyzed in this report includes those people who lived in Alameda County in both 1965, when they entered the study, and 1983. An analysis of the demographic differences between those people included in the analysis and those excluded revealed that the people living outside Alameda County were more likely to be male, younger, and white; to have more than 13 years of education; and to have higher mean income. We must be careful about generalizing our findings to other larger populations.

Overall, the findings of this exploration into the role of neighborhood social environmental characteristics are striking. Of course, many important questions remain to be answered. These include: 1) How can social environment be best measured? 2) What are people's qualitative experiences in different types of areas? 3) How does social environment influence health behaviors? and 4) What are the factors that determine where people live? Since area is a product of economics, historical events, social structure, public policy, and cultural practices, these investigations should be conducted in many locations. Ultimately, the goal of these investigations should be to develop interventions for disease prevention and health promotion. When we better understand the role of social environment and the mechanisms through which it influences people's health, we might be able to implement programs that target both people and places.

\section{ACKNOWLEDGMENTS}

Supported by National Heart, Lung, and Blood Institute grant T32 HL07365 (IHY). Additional support was provided by National Institute on Aging grant 5 R37 AG11375.

The authors thank. Richard Cohen and Long Ngo for statistical support and Dr. S. Leonard Syme and Jennifer L. Balfour for comments on earlier drafts.

\section{REFERENCES}

1. Jenkins CD, Tuthill RW, Tannenbaum SI, et al. Social stressors and excess mortality from hypertensive diseases. I Hum Stress 1979;5:29-40.

2. Neser WB, Tyroler HA, Cassel JC. Social disorganization and stroke mortality in the black population of North Carolina. Am J Epidemiol 1971;93:166-75.

3. Haan M, Kaplan GA, Camacho T. Poverty and health: prospective evidence from the Alameda County Study. Am J Epidemiol 1987;125:989-98.

4. Borrell C, Arias A. Socioeconomic factors and mortality in urban settings: the case of Barcelona, Spain. J Epidemiol Community Health 1995;49:460-5.

5. Morris JN, Blane DB, White IR. Levels of mortality, education, and social conditions in the 107 local education authority areas of England. I Epidemiol Community Health 1996;50: 15-17.

6. McLoone P, Boddy FA. Deprivation and mortality in Scotland, 1981 and 1991. BMJ 1994;309:1465-70.

7. Sloggett A, Joshi H. Higher mortality in deprived areas: community or personal disadvantage? BMJ 1994;309:1470 4 .

8. McCarron PG, Davey Smith G, Womersley JJ. Deprivation and mortality in Glasgow: changes from 1980 to 1992 . BMJ 1994;309:1481-2.

9. Eames M, Ben-Shlomo Y, Marmot MG. Social deprivation and premature mortality: regional comparison across England. BMJ 1993;307:1097-1102.

10. Carstairs V, Morris R. Deprivation and mortality: an alternative to social class? Community Med 1989;11:210-19.

11. Townsend $P$, Phillimore $P$, Beattie A. Health and deprivation: inequality and the North. London, England: Croom Helm, 1988.

12. LeClere FB, Rogers RG, Peters KD. Ethricity and mortality in the United States: individual and community correlates. Soc Forces 1997;76:169-98.

13. Anderson RT, Sorlie P, Backlund $E$, et al. Mortality effects of community socioeconomic status. Epidemiology 1997;8:42-7.

14. Kaplan GA. People and places: contrasting perspectives on the association between social class and heaith. Int J Health Serv 1996;26:507-19.

15. O'Campo P, Xue X, Wang MC, et al. Neighborhood risk factors for low birthweight in Baltimore City: a multilevel analysis. Am I Public Health 1997;87:1113-18.

16. Diez-Roux AV, Nieto J, Muntaner C, et al. Neighborhood environments and coronary heart disease: a multilevel analysis. Am 
J Epidemiol 1997;146:48-63.

17. Macintyre S, Maclver S, Sooman A. Area, class, and health: should we be focusing on places or people? I Soc Policy 1993; 22:23 3-34.

18. Lynch K. A theory of good city form. Cambridge, England: MIT Press, 1981.

19. Jacobs J. The death and life of great American cities. 2nd ed. New York, NY: The Modern Library, 1993.

20. Sooman A, Macintyre S. Health and perceptions of the local environment in socially contrasting neighbourhoods in Glasgow. Health Place 1995; ]:27-40.

21. Berkman LF, Breslow L, eds. Health and ways of living: the Alameda County Study. New York, NY: Oxford University Press, 1983.

22. Hochstim JR. Health and ways of living. In: Kessler II, Levin $\mathrm{ML}$, eds. The community as an epidemiologic laboratory. Baltimore, MD: The Johns Hopkins University Press, 1970: 149-76.

23. Sampson RJ. What "community" supplies. In: Ferguson RF, Dickens WT, eds. The future of community development: a socia] science symthesis. Washington, DC: Brookings Institution Press, 1998.

24. Massey DS, Fong E. Segregation and neighborhood quality: blacks, Hispanics, and Asians in the San Francisco metropoli$\tan$ area. Soc Forces 1990;69:15-32.

25. Bauman JF. Public housing, race, and renewal: urban planning in Philadelphia, 1920-1974. Philadelphia, PA: Temple University Press, 1987.

26. Hirsch AR. Making the second ghetto: race and housing in Chicago, 1940-1969. Cambridge, England: Cambridge University Press, 1983.

27. Logan JR, Stearns LB. Suburban racial segregation as a nonecological process. Soc Forces 1981;60:61-73.

28. Squires GD. Capital and communities in black and white: the intersections of race, class, and uneven development. New
York, NY: State Universily of New York Press, 1994.

29. Shevky E, Bell W. Social area analysis: theory, illustrative application and computational procedures. Westport, CT: Greenwood Press, 1955.

30. Fisher LD, van Belle G. Biostatistics: a methodology for the health sciences. New York, NY: John Wiley \& Sons, Inc., 1993.

31. Blalock HM. Contextuaj-effects models: theoretical and methodological issues. Ann Rev Socjol 1984;10:353-72.

32. Bryk AS, Raudenbusb SW. Hierarchical linear models: applications and data analysis methods. Newbury Park, CA: Sage Publications, 1992.

33. Yen IH, Kaplan GA. Poverty area residence and changes in physical activity level: evidence from the Alameda County Study. Am J Public Health 1998;88:1709-12.

34. Yen IH, Kaplan GA. Poverty area residence and change in depression and perceived health status. Int I Epidemiol (In press).

35. Kasarda JD. Inner-city concentrated poverty and neighborhood distress: 1970 to 1990. Housing Policy Debate 1993; 4:253-302.

36. Haan M, Kaplan GA, Syme SL. Socioeconomic status and health: old observations and new thoughts. In: Bunker JP, Gomby DS, Kelyrer BH, eds. Pathways to health: the role of social factors. Menlo Park, CA: Henry J. Kaiser Family Foundation, 1989:76-135.

37. Wing $S$, Casper $M$, Riggan $W$, et al. Socioenvironmental characteristics associated with the onset of decline of ischemic heart disease mortality in the United States. Am J Public Health 1988;78:923-6.

38. US Department of Health and Human Services. Anthropometric reference data and prevalence of overweight: United States, 1976-1980. Hyattsville, MD: National Center for Health Statistics, October 1987. (DHHS publication no. (PHS) 87-1688). 